\title{
Effect of Incorporation of Rice Husk Ash Instead of Cement on the Performance of Steel Fibers Reinforced Concrete
}

\author{
Osama Zaid ${ }^{1 *}$, Jawad Ahmad 1*, Muhammad Shahid Siddique ${ }^{1}$ and Fahid Aslam ${ }^{2}$ \\ ' Department of Civil Engineering, Military College of Engineering, Risalpur, Sub Campus of National University of Science \\ and Technology, Islamabad, Pakistan, ${ }^{2}$ Department of Civil Engineering, College of Engineering in Al-Kharj, Prince Sattam \\ Bin Abdulaziz University, Al-Kharj, Saudi Arabia
}

OPEN ACCESS

Edited by:

Ali Kashani,

University of New South Wales,

Australia

Reviewed by:

Souradeep Gupta,

Indian Institute of Science (IISC), India

Aziz Hasan Mahmood,

University of New South Wales,

Australia

*Correspondence:

Osama Zaid

osamazaidmarwat@gmail.com

Jawad Ahmad

jawadcivil13@scetwah.edu.pk

Specialty section:

This article was submitted to

Structural Materials,

a section of the journal

Frontiers in Materials

Received: 08 February 2021 Accepted: 20 April 2021

Published: 30 June 2021

Citation:

Zaid O, Ahmad J, Siddique MS and Aslam F (2021) Effect of

Incorporation of Rice Husk Ash

Instead of Cement on the

Performance of Steel Fibers

Reinforced Concrete.

Front. Mater. 8:665625.

doi: 10.3389/fmats.2021.665625
The production of rice is significant worldwide; the husk produced is generally used as a combustible material for the preparation of paddies, delivering energy through direct combustion as well as by gasifying. Annually, 7.4 million tons of Rice Husk Ash (RHA) is produced and poses an incredible danger to the environment, harming the land and the encompassing zone where it is unloaded. In the transformation of rice husk to ash, the ignition cycle eliminates the natural products, leaving silica-rich remains. These silica-rich remains have proven to have potential to be utilized in concrete as a limited substitution of cement to enhance the concrete compressive strength. Steel fibers' incorporation increases the concrete tensile strength, balances out concrete samples, and changes their brittle behavior to a more ductile response. In the current study, the influence of various doses of Rice Husk Ash (RHA) used in concrete in the presence and absence of steel fibers and concrete performance has been examined. A total of nine mixes have been designed: one was a control, four were without steel fibers containing only $\mathrm{RHA}$, and the last four mixed RHA with steel fibers from 0.5 to $2 \%$. Tests with 5,10 , 15 , and $20 \%$ percentages of $\mathrm{RHA}$ replacing the concrete have been targeted. Results have been compared with the reference samples and the reasonability of adding Rice Husk Ash to concrete has been studied. From the results, it was noted that about $10 \%$ of cement might be replaced with Rice Husk Ash mixed in with steel fibers with almost equal compressive strength. Replacing more than $15 \%$ of cement with RHA will produce concrete with a low performance in terms of strength and durability.

Keywords: concrete, steel fibers, rice husk ash, compressive strength, superplasticizer

\section{INTRODUCTION}

Concrete is a frequently used construction and building material, which is sufficiently strong, impermeable, and durable. Among the ingredients of concrete, cement is an expensive material, and its demand is persistently increasing all over the globe. Hence, to control the cost of construction, it is important to utilize modern waste materials, mineral admixtures, and other materials to accommodate the increasing use of concrete. Agricultural waste, such as rice husk ash (RHA), can be used instead of cement in concrete making, producing efficient concrete with improved 
concrete properties like impermeability, workability, strength, and corrosion of steel reinforcement. For reasonable improvement of concrete, increasing the use of cement raw materials must be preserved. RHA is an exceptionally responsive pozzolanic material used as an Ordinary Portland Cement substitution. It is a good option to utilize RHA in concrete because it will increase concrete workability.

A lot of studies have been performed to examine the possible use of Rice Husk Ash in concrete. Tay (1990) confirmed a reduction in concrete compressive strength which is nearly relative to the amount of ash in the mixed cement (Udoeyo and Dashibil, 2002). Concrete samples with sawdust ash (SDA) substitution from 20 to $25 \%$ demonstrated a compressive strength, with strength diminishing with higher ash content (Jaturapitakkul and Roongreung, 2003). It was also shown that mortar of $\mathrm{CaC} 2$ residue compressive strength and Rice Husk Ash can be more than $16.5 \mathrm{Mpa}$ after 28 days of curing days and expand to 20.2 Mpa after 180 days of curing (Qing-ge et al., 2004). Further studies have demonstrated that, in the substitution of cement with Rice Husk Ash, concrete compressive strength is clearly increased (Sakr, 2006). It was also shown that ilmenite concrete had the highest compressive strength when blended in with $10 \%$ steel fibers (Tangchirapat et al., 2009). One study replaced $10 \%$ cement with palm ash and showed palm oil fuel ash mortar compressive strength was $100-102 \%$ of cement Type I mortar after curing for 90 days (Ferraro et al., 2010). Using white cement, up to $15 \%$ of RHA may be well mixed (Xu et al., 2012). It was also demonstrated that that about $20 \%$ of Rice Husk Ash, Fine Aggregate, Palm oil fuel ash, or wheat straw ash can be utilized to replace cement without influencing the physical properties of glass fiber reinforced concrete (GFRC) (Zain et al., 2011). A final study examined the concrete compressive strength over varying fineness of RHA replacing cement at about $15 \%$ and indicated that the concrete strength was enhanced.

Rice husk is a significant agricultural by-product and is produced during the husk removal cycle of paddy rice. In a 2002 environmental review, it was shown that the yearly worldwide formation of paddy was 0.579 billion tons (Xu et al., 2012). India is close to China in terms of paddy production, making up $31.2 \%$ of the globe's creation. Removal of rice husk is a significant problem as inappropriate removal causes natural issues (Zain et al., 2011). One technique is using the rice husk as a replacement for concrete. In concrete, RHA could be utilized as a mineral admixture due to its profoundly siliceous nature if the rice husk is kept at a constrained temperature between 700 and $800^{\circ} \mathrm{C}$ (James and Rao, 1986). Through this consuming cycle, the carbon amount in rice husk is burnt off and all that is left is silica residue (O'Connell et al., 2007). The huge pozzolanic behavior is an important quality for utilizing it as a replacement or an admixture (mineral) in concrete (Ahmad et al., 2021). The viable use of Rice Husk Ash in concrete relies upon its particle size (Kishore et al., 2011). Given the checking electron magnifying lens contemplates, it has been proven that Rice Husk Ash is a permeable pozzolanic material and includes a huge number of sets of size 1-10 $\mu \mathrm{m}$ (Mehta, 1992; Uduweriya et al., 2010). Fine grains work as a filler on the pore structure and more confine enhancement of RHA particles produces more hydration. Adding
Rice Husk Ash to concrete improves the strength. However, when a low water/cement ratio is used, a weak performance is seen in Rice Husk Ash concrete (Giaccio et al., 2007; Vijai et al., 2012).

Various research shows that mechanical and durability characteristics considerably improved with the incorporation of fibers (Ahmad et al., 2020a). The impact of polypropylene fibers and silica fume improved the mechanical properties of expansive-cement concrete (Toutanji, 1999). According to Toutanji (1999), characteristics considered include those of the change of length, fresh mix properties, rapid chloride permeability, flexural conduct, compressive strength, and bond of hardened concrete. The silica fume amount utilized was 7 and $9 \%$ and volume of fiber amount was $0.15,0.20$, and $0.30 \%$. Results display that utilization of $7 \%$ silica fume joined with 0.20 percent volume of fiber volume fraction brings about an optimum mix design for repair applications from the angles of length change, workability, strength, bond, and permeability (Nuruddin et al., 2011). Researchers examined the impacts of sodium hydroxide molarity and superplasticizer on the workability, compressive strength, and microstructure of (SCGC) Self Compacting Geopolymer Concrete. Outcomes

\begin{tabular}{lclc}
\hline \multicolumn{2}{c}{ TABLE 1 | Physical and chemical property of OPC. } & \\
\hline $\begin{array}{l}\text { Chemical } \\
\text { property }\end{array}$ & Percentage (\%) & Physical property & Results \\
\hline $\mathrm{CaO}$ & 62.7 & Size & $\leq 75 \mu$ \\
$\mathrm{SiO}_{2}$ & 25.9 & Fineness & $92 \%$ \\
$\mathrm{Al}_{2} \mathrm{O}_{3}$ & 8.4 & Normal & $28 \%$ \\
$\mathrm{Fe}_{2} \mathrm{O}_{3}$ & 1.7 & consistency & \\
& & Initial & $38 \mathrm{~min}$ \\
$\mathrm{MgO}$ & 2.5 & setting time & \\
$\mathrm{SO}_{3}$ & & Final & $412 \mathrm{~min}$ \\
$\mathrm{~K}_{2} \mathrm{O}$ & 1.9 & setting time & \\
$\mathrm{Na}_{2} \mathrm{O}$ & 2.4 & Specific surface & $322 \mathrm{~m} / \mathrm{kg}$ \\
& 0.2 & Soundness & $1.70 \%$ \\
& & 28-days compressive & $42 \mathrm{Mpa}$ \\
\hline
\end{tabular}

TABLE 2 | Physical property of steel fibers.

\begin{tabular}{lc}
\hline Physical property & Results \\
\hline Length & $35 \mathrm{~mm}$ \\
Diameter & $0.55 \mathrm{~mm}$ \\
Aspect ratio (L/d) & 64 \\
Tensile strength & $415 \mathrm{Mpa}$ \\
Young'sModulus & $3.6 \mathrm{GPa}$ \\
\hline
\end{tabular}

TABLE 3 | Physical properties of fine and coarse aggregate.

\begin{tabular}{lcc}
\hline Physical property & Fine aggregate & Coarse aggregate \\
\hline Bulk density $\left(\mathrm{kg} / \mathrm{m}^{3}\right)$ & 1,586 & 1,535 \\
Moisture content & $1.8 \%$ & $1.25 \%$ \\
Absorption capacity & $5.28 \%$ & $2.13 \%$ \\
Fineness modulus & 2.93 & 4.7 \\
Particle size & $4.75-0.75 \mathrm{~mm}$ & $30-4.75 \mathrm{~mm}$
\end{tabular}


showed that workability and performance enhanced with the increase in superplasticizer content. The Rice Husk Ash produced from the consumption of husk in heater at controlled temperature satisfies the actual qualities and compound piece of mineral admixtures. The pozzolanic behavior of Rice Husk Ash relies on the silica crystallization stage, silica percentage, and surface zone and size of ash. The measure of carbon amount in RHA should be small. In the event that the carbon content is more in RHA, the strength of concrete will be less.

In the current study, lab tests were performed to analyze the use of Rice Husk Ash alongside superplasticizer (with the presence and absence of steel fibers with $0 \%, 0.5 \%$, $1.0 \%, 1.5 \%$, and $2.0 \%$ ) as a cement substitution ingredient in

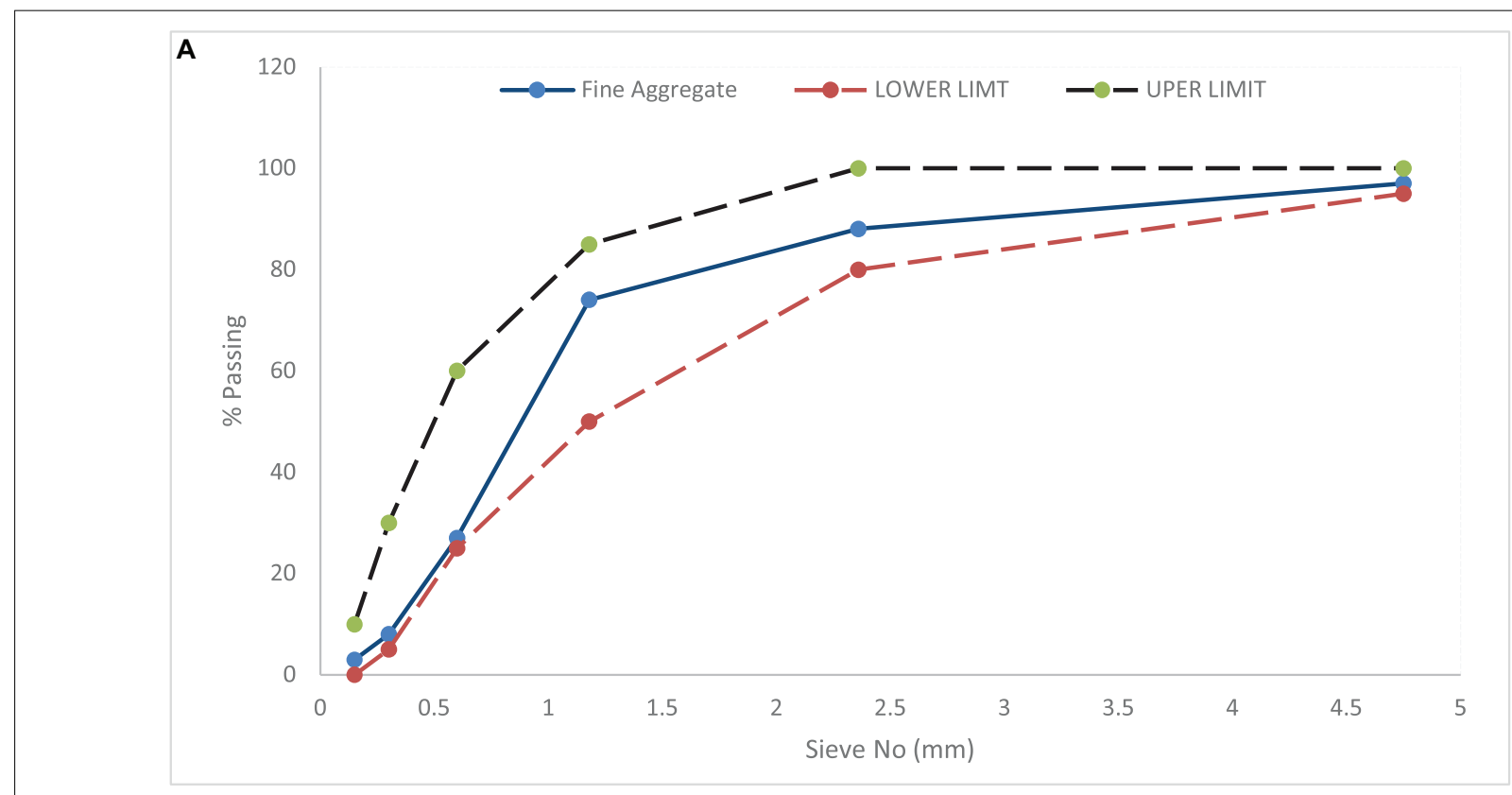

B

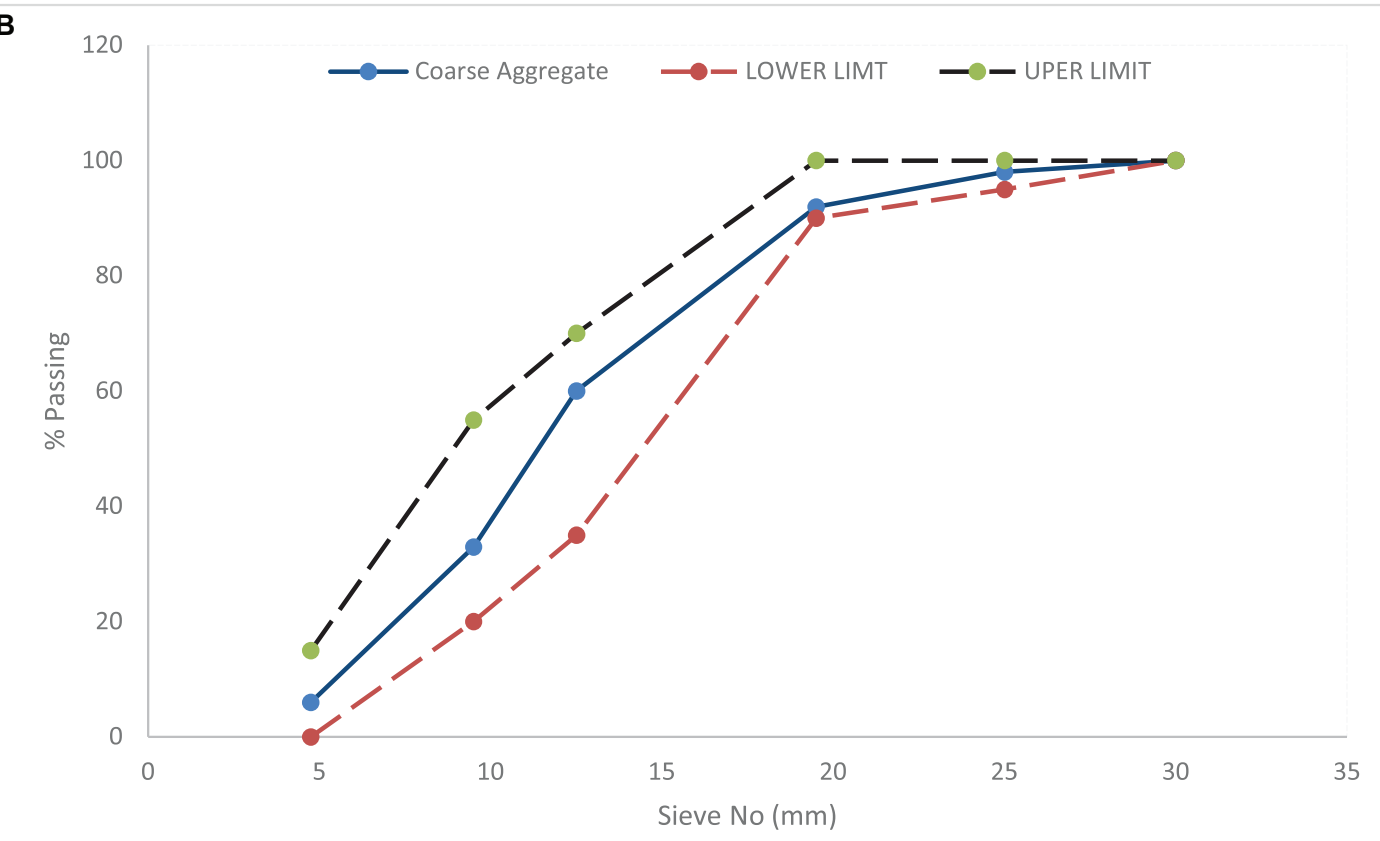

FIGURE 1 | (A) Gradation Curve of Fine Aggregate, (B) Gradation curve of Coarse Aggregate. 
TABLE 4 | Chemical composition of rice husk ash.

\begin{tabular}{lc}
\hline Chemical & Rice husk ash (\%) \\
\hline $\mathrm{CaO}$ & 12.56 \\
$\mathrm{SiO}_{2}$ & 62.3 \\
$\mathrm{Al}_{2} \mathrm{O}_{3}$ & 10.11 \\
$\mathrm{Fe}_{2} \mathrm{O}_{3}$ & 6.48 \\
$\mathrm{MgO}$ & 3.5 \\
$\mathrm{SO}_{3}$ & 0.61 \\
$\mathrm{~K}_{2} \mathrm{O}$ & 2.09 \\
$\mathrm{Na}_{2} \mathrm{O}$ & 0.049 \\
\hline
\end{tabular}

concrete. The use of steel fibers might increase the cement stabilized samples and change concrete brittle behavior to ductile behavior. The impact of the various ratios of RHA incorporated into concrete which contains superplasticizer with and without steel fibers on concrete performance has been
TABLE 5 | Physical property of superplasticizer.

\begin{tabular}{lc}
\hline Property & Result \\
\hline Color & Brown liquid \\
Air entrainment & 1.48 at $25^{\circ} \mathrm{C}$ \\
Chloride content & Nil to BS $5075 / \mathrm{BS}:$ EN934 \\
Specific gravity & $1.18 @ 25\left(^{\circ} \mathrm{C}\right.$ \\
\hline
\end{tabular}

studied. Tests with $0,5,10,15$, and $20 \%$ percentage of Rice Husk Ash replacing the cement have been tried. The outcomes have been compared with the control samples and the feasibility of adding Rice Husk Ash to concrete has been contemplated. From studying previous literature, it is concluded that incorporation of steel fibers affects concrete workability, so using a superplasticizer was important to keep concrete in a flowable state.

TABLE 6 | Quantification of materials.

\begin{tabular}{|c|c|c|c|c|c|c|c|c|c|c|}
\hline \multirow[t]{2}{*}{ Mix ID } & \multicolumn{3}{|c|}{ Mix proportion (\%) } & \multirow{2}{*}{$\begin{array}{l}\text { Cement } \\
\left(\mathrm{Kg} / \mathrm{m}^{3}\right)\end{array}$} & \multirow[t]{2}{*}{ RHA } & \multirow{2}{*}{$\begin{array}{c}\text { Steel fibers } \\
\text { (kg) }\end{array}$} & \multirow{2}{*}{ Water (kg) } & \multirow{2}{*}{$\begin{array}{c}\text { Sand } \\
\left(\mathrm{kg} / \mathrm{m}^{3}\right)\end{array}$} & \multirow{2}{*}{$\begin{array}{c}\text { Coarse } \\
\text { aggregate } \\
\left(\mathbf{k g} / \mathrm{m}^{3}\right)\end{array}$} & \multirow{2}{*}{$\begin{array}{c}\text { Superplasticizer } \\
\text { (kg) }\end{array}$} \\
\hline & Cement & RHA & Steel Fibers & & & & & & & \\
\hline Mix 1 & $100 \%$ & $0 \%$ & $0 \%$ & 375 & - & - & 165 & 650 & 1,310 & $0 \%$ \\
\hline $\operatorname{Mix} 2$ & $95 \%$ & $5 \%$ & $0 \%$ & 365.25 & 18.75 & - & 165 & 650 & 1,310 & $0 \%$ \\
\hline Mix 3 & $90 \%$ & $10 \%$ & $0 \%$ & 337.5 & 37.5 & - & 165 & 650 & 1,310 & $0 \%$ \\
\hline Mix 4 & $85 \%$ & $15 \%$ & $0 \%$ & 318.75 & 56.25 & - & 165 & 650 & 1,310 & $0 \%$ \\
\hline Mix 5 & $80 \%$ & $20 \%$ & $0 \%$ & 300 & 75 & - & 165 & 650 & 1,310 & $0 \%$ \\
\hline Mix 6 & $95 \%$ & $5 \%$ & $0.5 \%$ & 365.25 & 18.75 & 1.875 & 165 & 650 & 1,310 & 2.50 \\
\hline Mix 7 & $90 \%$ & $10 \%$ & $1.0 \%$ & 337.5 & 37.5 & 3.75 & 165 & 650 & 1,310 & 2.50 \\
\hline Mix 8 & $85 \%$ & $15 \%$ & $1.5 \%$ & 318.75 & 56.25 & 5.625 & 165 & 650 & 1,310 & 2.50 \\
\hline Mix 9 & $80 \%$ & $20 \%$ & $2.0 \%$ & 300 & 75 & 7.5 & 165 & 650 & 1,310 & 2.50 \\
\hline
\end{tabular}

\section{7 days $\square 21$ days $\square 28$ days}

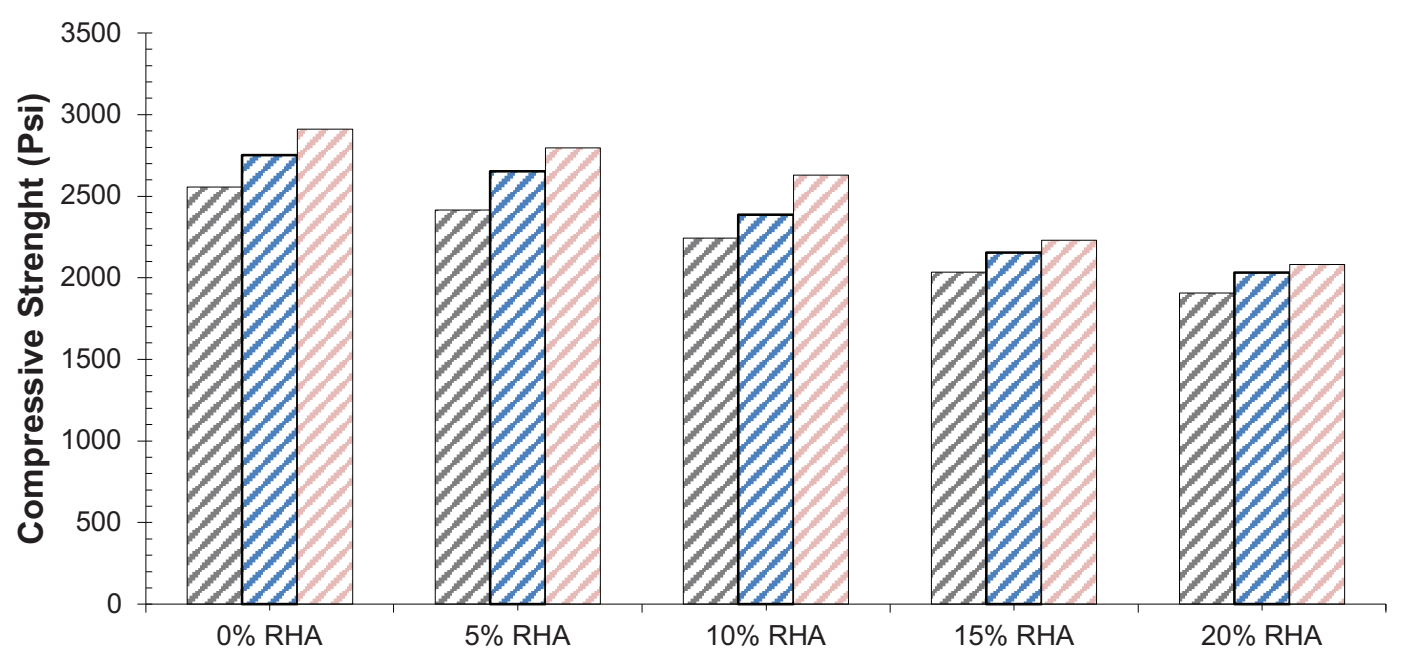

FIGURE 2 | Compressive strength (without steel fibers and superplasticizer). 


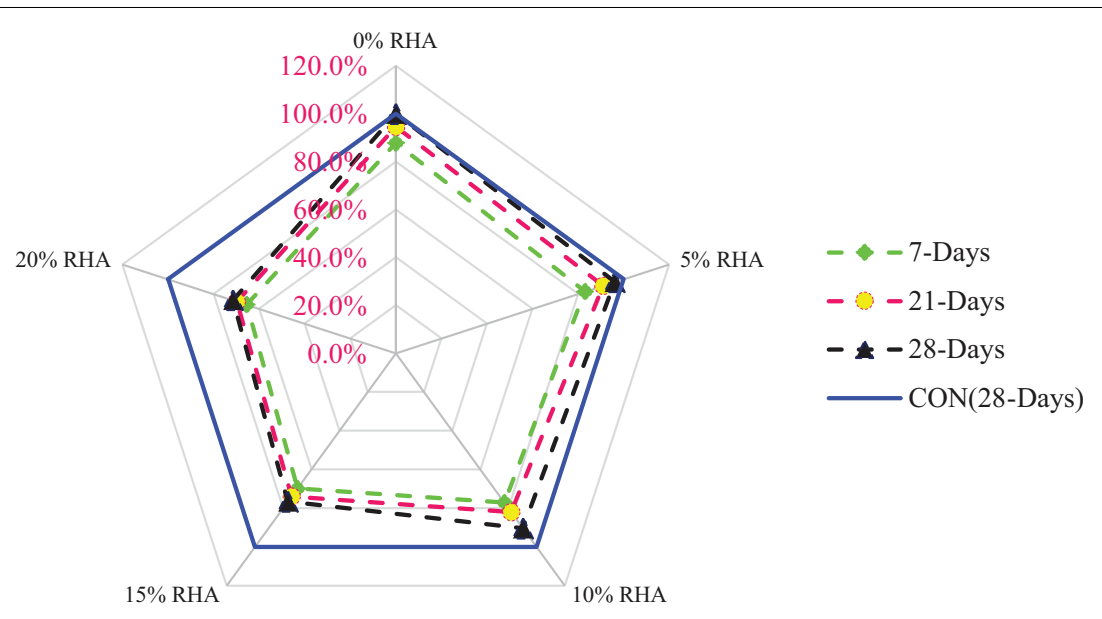

FIGURE 3 | Relative analysis compressive strength (without steel fibers and superplasticizer).

\section{$\square 7$ days $\square 21$ days $\square 28$ days}

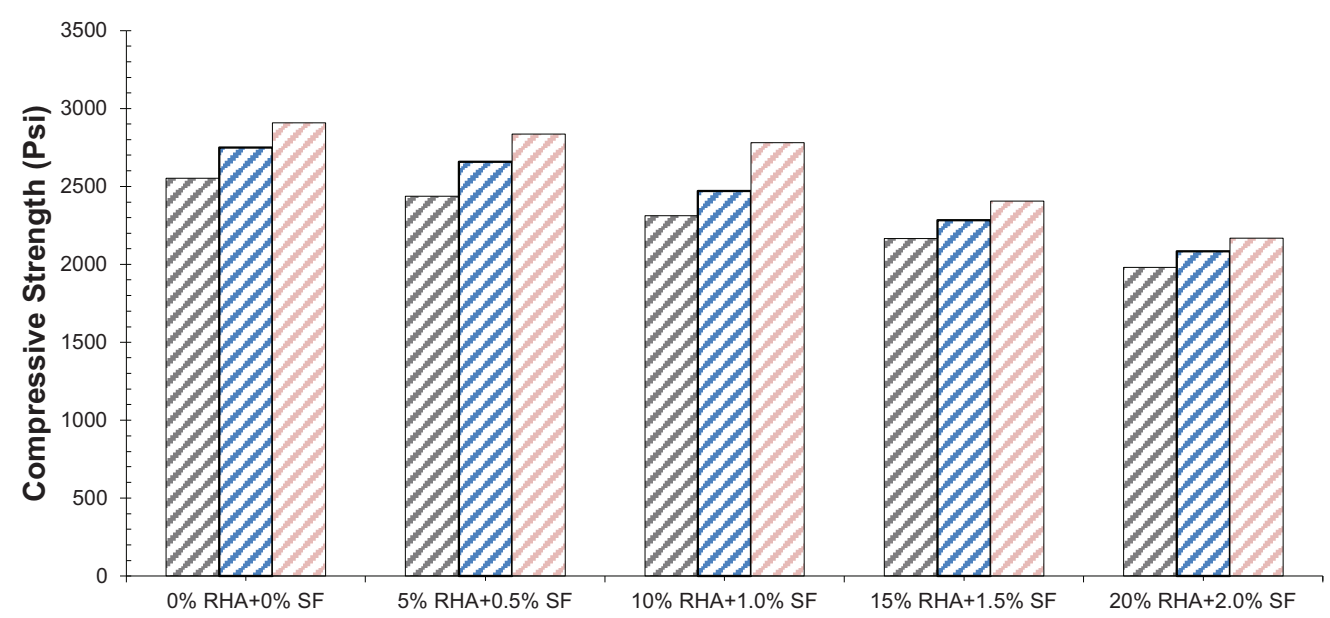

FIGURE 4 | Compressive strength (with steel fibers and superplasticizer).

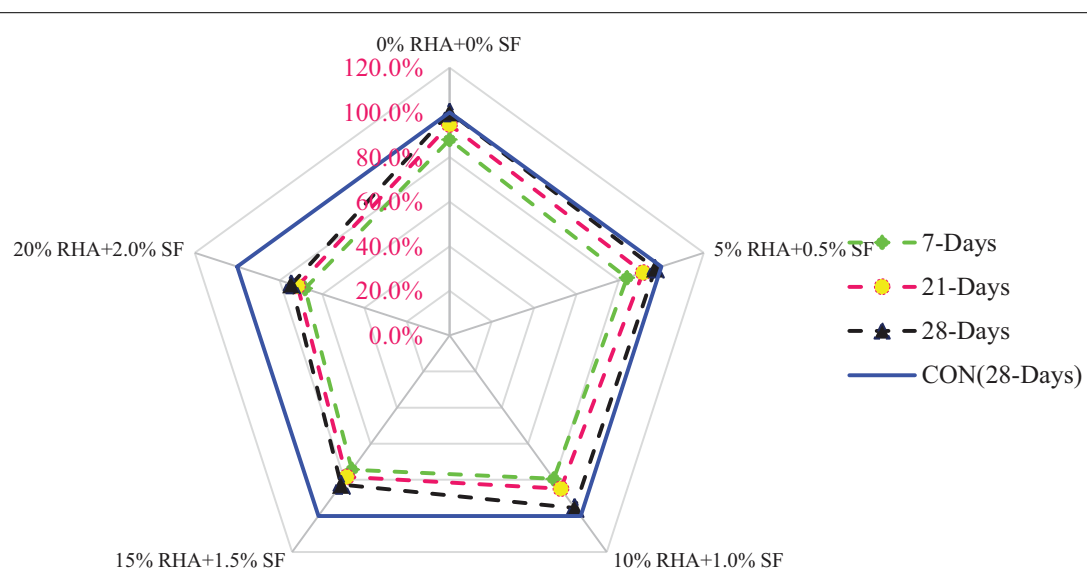

FIGURE 5 | Relative analysis of compressive strength (with steel fibers and superplasticizer). 


\section{EXPERIMENTAL PROGRAM}

\section{Methods and Materials \\ Cement}

The primary binder that was used in all mixes was Ordinary Portland Cement, which is type I general-purpose cement as per ASTM C 150 [22]. The chemical and physical properties of Ordinary Portland Cement are displayed in Table $\mathbf{1 .}$

\section{Steel Fibers}

Hook end steel fibers with a length of $35 \mathrm{~mm}$ were glued together and were used in different percentages. Their properties are given in Table 2.

\section{Aggregates}

For fine aggregates, typical natural sand, obtained from Lawrancepaur, was utilized in saturated surface dry conditions in entire blends. The coarse aggregate used in this study was obtained from Margalla in saturated surface dry condition and was used in all blends; the maximum size of the coarse aggregate was $30 \mathrm{~mm}$. Tests were performed to determine aggregate physical parameters, which are shown in Table 3, while gradation curves of fine and coarse aggregate as per ASTM C 33 (ASTM C 33/C33M, 2008) are shown in Figures 1A,B, respectively.

\section{Rice Husk Ash}

Rice husk is obtained from the rice milling industry because it is a byproduct. Research has demonstrated that heating rice husk at a temperature of $700^{\circ} \mathrm{C}$ makes a powder that has a sufficient structure for pozzolanic materials. Research has also indicated that, because of RHA's high surface area, the Rice Husk Ash can be used in concrete as a mineral admixture. RHA reduces the permeability of concrete when used as a mineral admixture. Rice Husk Ash utilized in the present study was gray, had a $\mathrm{pH}$ of 7.4,
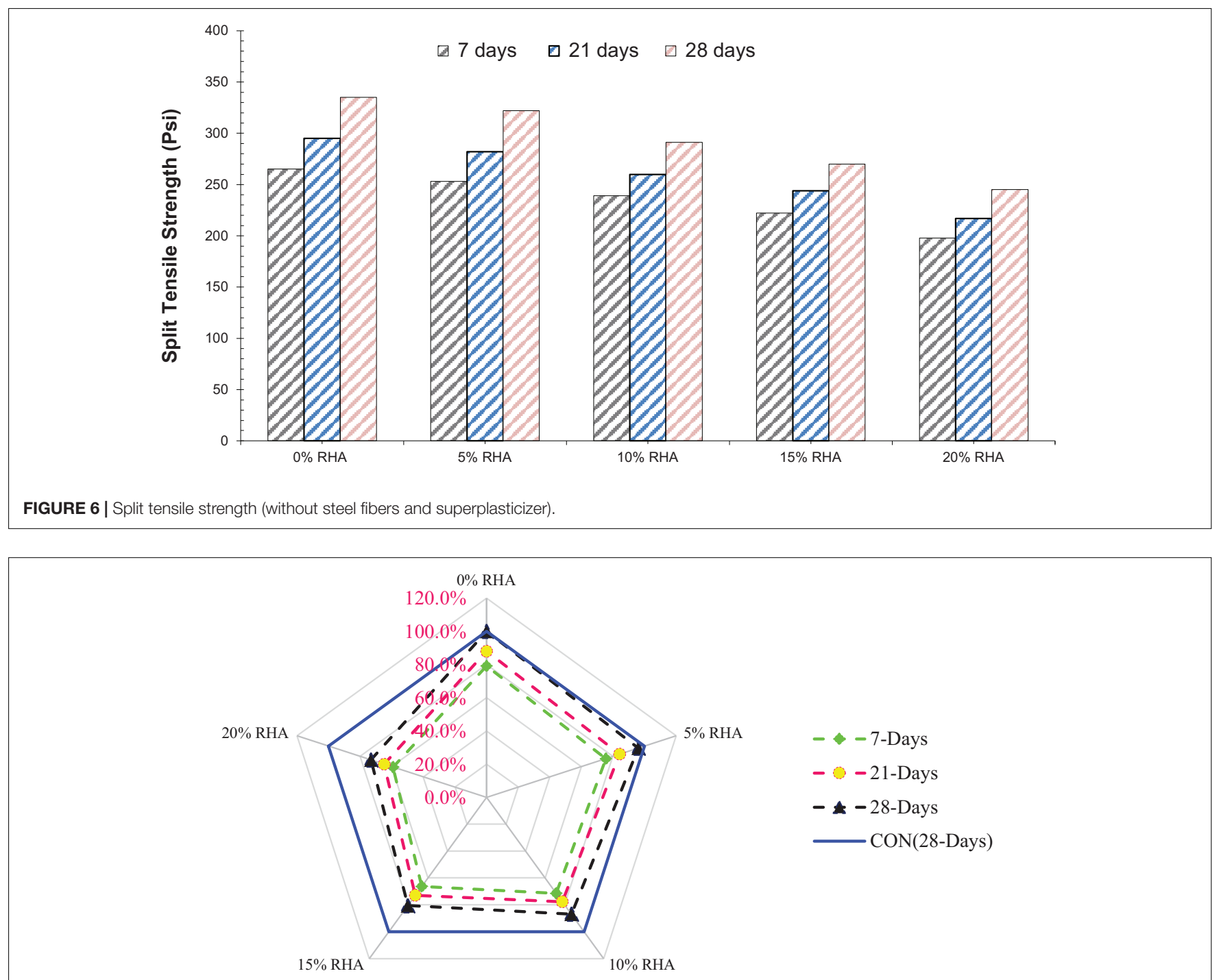

$$
\begin{aligned}
& -\downarrow-7 \text {-Days } \\
& -\infty-21 \text {-Days } \\
& -\star-28 \text {-Days } \\
& \longrightarrow \text { CON(28-Days) }
\end{aligned}
$$

FIGURE 7 | Relative analysis split tensile strength (without steel fibers and superplasticizer). 
and contained silica of $62.3 \%$. The typical chemical composition is shown in Table 4.

\section{Water}

The study revealed that the $\mathrm{pH}$ of water for mixing in concrete should be in the range of 6 and 8 (Zain et al., 2011). In this study, clean drinking water was used, which was obtained from commercial tube well.

\section{Superplasticizer}

In the present research, Conplast SP 430 superplasticizer was used. It is included commonly in the scope of $0.6-1.3 \%$ by cement weight. The utilization of a superplasticizer makes pumpable concrete and concrete which is more workable. In the current investigation, a $0.8 \%$ superplasticizer was utilized to control test samples. Conplast SP430 meets with BS 5075, BS: EN 934-2 (ENTS, 2009), and with ASTM C494 as Type A and Type F
[25], contingent upon the measurements utilized. In Table 5 its physical properties are provided.

\section{Test Mixing Procedure and Size of Specimen}

The complete investigation program was planned so that it was done within 30 days from the date of acquisition of cement to diminish the negative effects on properties of concrete as a result of storing cement. A 1:1.5:3 ratio was used for concrete making. First, the cement, sand, and coarse aggregates were dry mixed for 60 seconds, and then water was added along with RHA, and then the mixture was mixed again for $2 \mathrm{~min}$. The aggregates used to manufacture concrete were used in saturated surface dry conditions. For concrete, 1:1.5:3 ratios were used as per ASTM C 39 (Materials ASFTA, 2012). For sampling standard size of cylinders, 6 inch $\times 12$ inches were utilized to

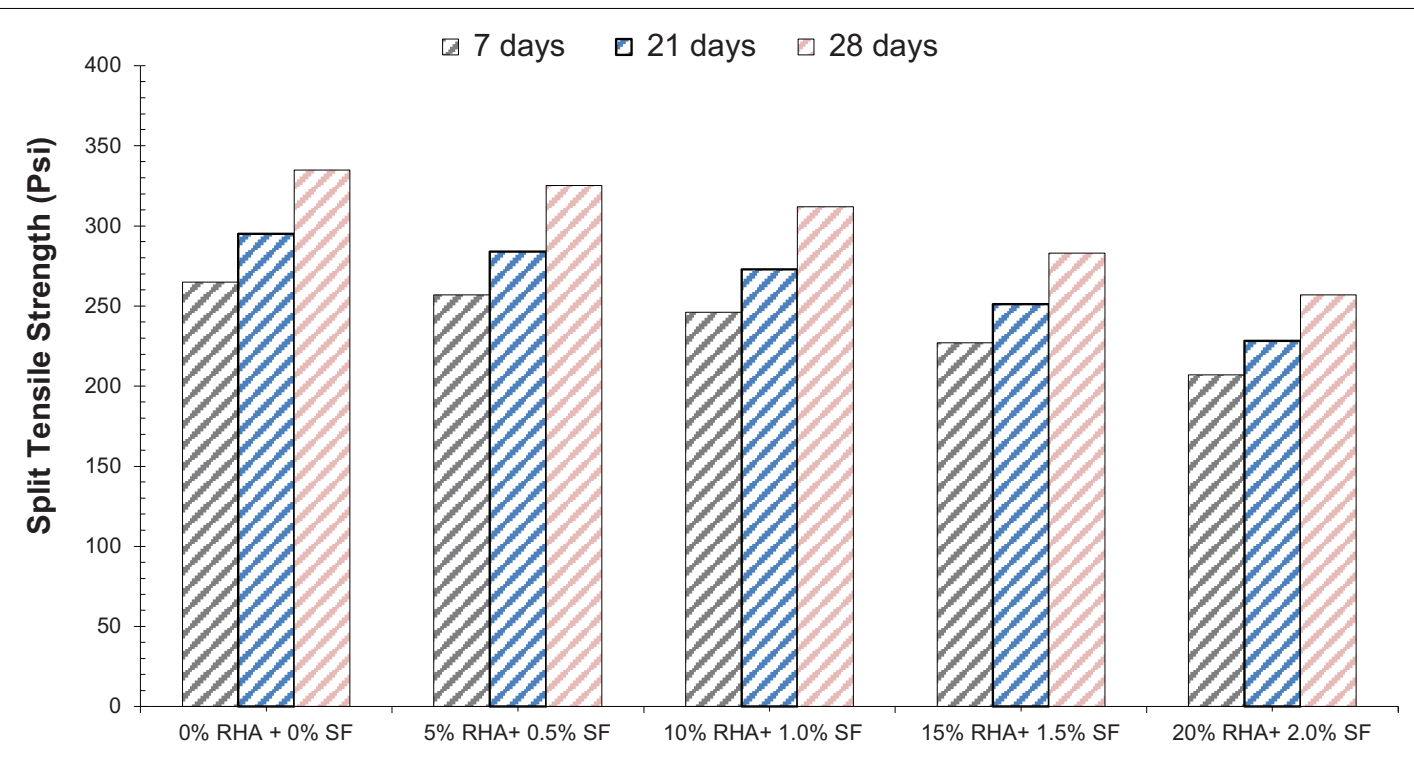

FIGURE 8 | Split tensile strength (with steel fibers and superplasticizer).

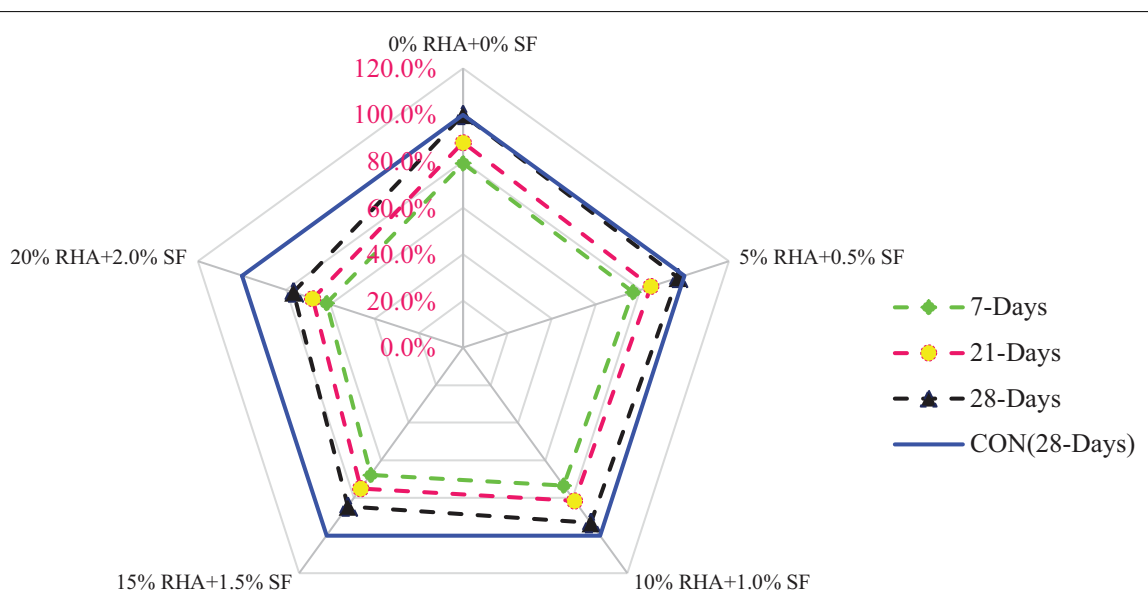

FIGURE 9 | Relative analysis split tensile strength (with steel fibers and super plasticizer). 
determine the concrete compressive strength as per ASTM C 39 (C39/C39M A, 2003) and split tensile strength as per ASTM C 496 (Designation, 1976). Water absorption tests as per ASTM C 642-13 (C642-13 A, 2013), density as per ASTM C 642-13 (C642-13 A, 2013), and volume of voids test as ASTM C 64213 (C642-13 A, 2013) of concrete were performed at 7, 21, and 28 days after curing. During sampling, concrete was packed with 3 layers, with each layer being compacted 25 times. Adding of RHA to concrete with varying dosages $(0,5,10,15$, and $20 \%)$ with and without steel fibers of different percentage $(0 \%, 0.5 \%$, $1.0 \%, 1.5 \%$, and $2.0 \%$ ) and keeping the dose of superplasticizer same were compared with normal control mixes, as shown in Table 6.
RESULTS AND DISCUSSION

\section{Compressive Strength Test on Concrete Cylinders With Cement Substituted With Rice Husk Ash (Without Steel Fibers and Superplasticizer)}

The results of the compressive strength test on concrete cylinders as per ASTM C 39 (C39/C39M A, 2003) with cement substituted with Rice Husk Ash (without superplasticizer and steel fibers) are displayed below in Figure 2.

It is a known fact that concrete strength increases with an increase in curing days. For normal concrete with 0\% RHA,
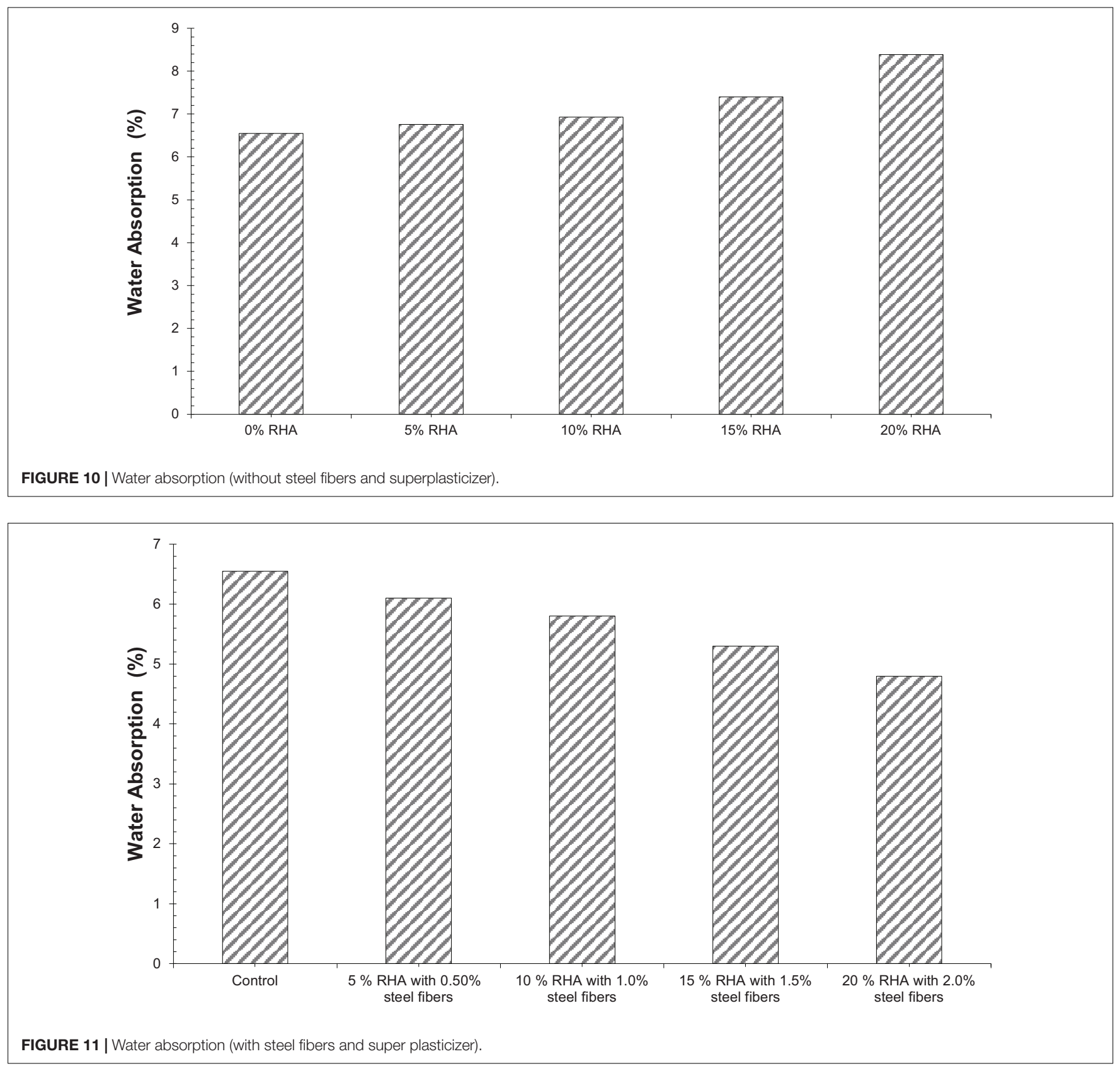
concrete compressive strength was 2,554 psi after 7 days of curing, 2,750 psi after 21 days of curing, and 2,910 psi after 28 days of curing. General trends show that compressive strength decreases with the addition of RHA (Mehta, 1992; Nehdi et al., 2003). For $5 \%$ of cement replaced with RHA, the strength decrease was $5.4,3.6$, and $3.9 \%$ after 7,21 , and 28 days of curing, respectively, as in comparison to control samples. For $10 \%$ cement replaced with Rice Husk Ash, the strength decrease was $12.1,13.2$, and $13.5 \%$ after 7,21 , and 28 days of curing, respectively, as in comparison to control samples. For 15\% cement replaced with Rice Husk Ash, the strength decrease was $20.3,21.7$, and $23.4 \%$ after 7,21 , and 28 days of curing, respectively, as in comparison to control samples. For $20 \%$ cement replaced with Rice Husk Ash, the strength decrease was $25.4,26.1$, and $28.5 \%$ after 7,21 , and 28 days of curing, respectively, as compared to control samples. From the outcomes, it is seen that increasing the amount of RHA used as a cement replacement decreases the concrete compressive strength. Upon replacement of 10\% RHA with cement, about a $12 \%$ decrease in compressive strength was noted. By further increasing doses of RHA, concrete strength would be affected significantly. Consequently, Rice Husk Ash up to $10 \%$ as replacement of cement is allowed in concrete without considerable change in compressive strength.

A relative analysis was carried out in which the 28 -days curing age compressive strength of the control mix was considered the relating mix, and from this, different blends with changing percentages of RHA are compared, as shown in Figure 3. At
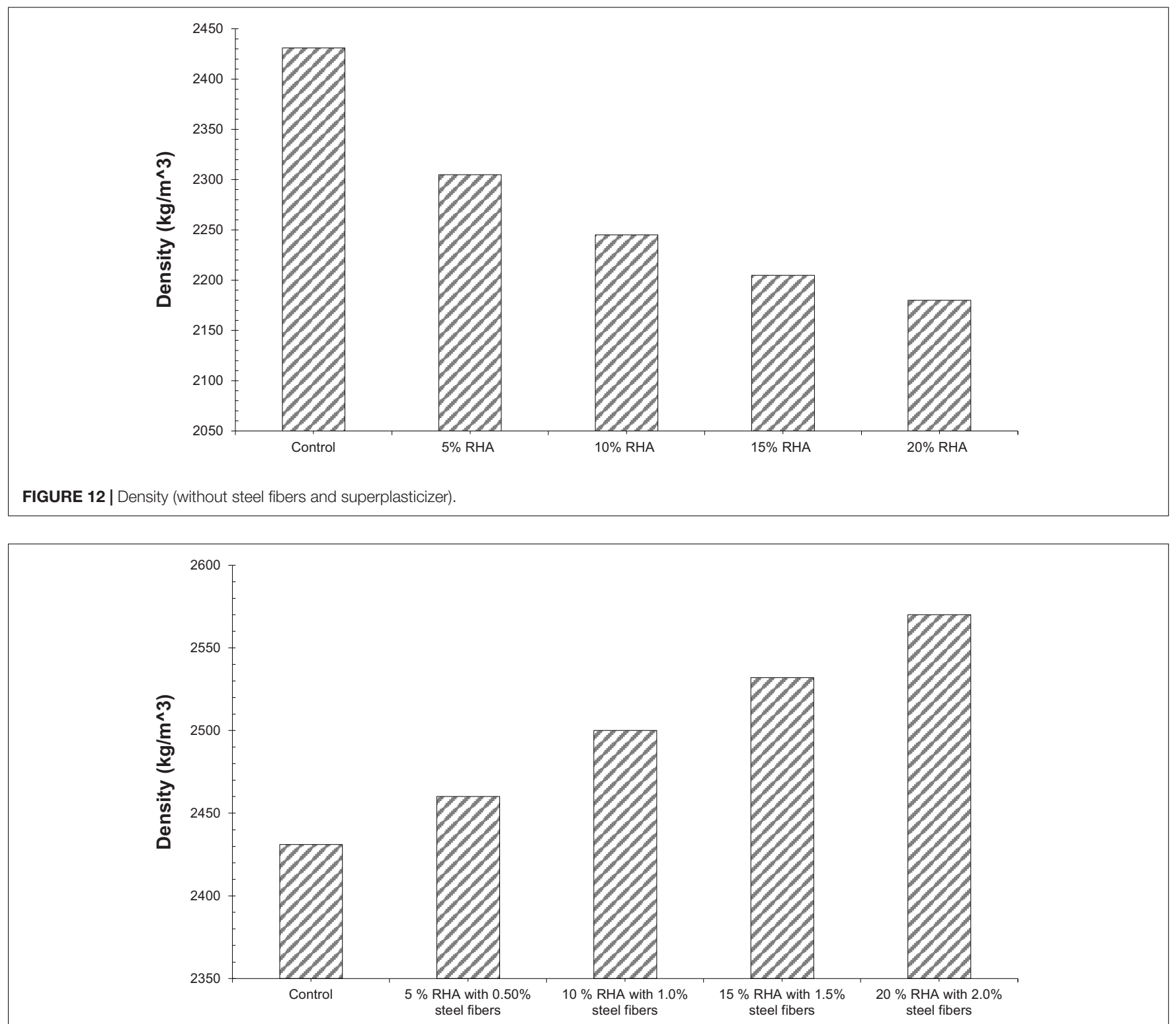

FIGURE 13 | Density (with steel fibers and superplasticizer). 
7 days of curing, compressive strength was about 19\% less than that of the control (28 days) at 10\% substitution with RHA (optimum dosage). As compared to the control, 10\% substitution with RHA (optimum dosage) showed 18\% less compressive strength at 21 days of curing. On day 28 of curing, compressive strength was only $9.0 \%$ less than that of the control (28 days) at $10 \%$ substitution with RHA (optimum dosage). As compared to the control, $20 \%$ substitution with RHA showed $31 \%$ less compressive strength at 7 days. On day 21 of curing, compressive strength was about $28 \%$ less than that of the control (28 days) at $20 \%$ substitution with RHA. At 28 days of curing, compressive strength was about $24 \%$ less as compared to control mix. It can be concluded that $10 \%$ substitution shows only $9.0 \%$ less as compared to control; this is not too much of a reduction in compressive strength and hence can be successfully utilized in concrete. Therefore, it is recommended to substitute up to $10 \%$ of cement with RHA.

\section{Compressive Strength Test on Concrete Cylinders With Cement Substituted With Rice Husk Ash (With Steel Fibers and Superplasticizer)}

Figure 4 illustrates the different concrete compressive strengths in which the cement is substituted with changed doses of Rice Husk Ash (with steel fibers and superplasticizer) with the curing age of concrete. Normal concrete with $0 \%$ Rice Husk Ash showed concrete compressive strength was 2,554 psi after 7 days curing,
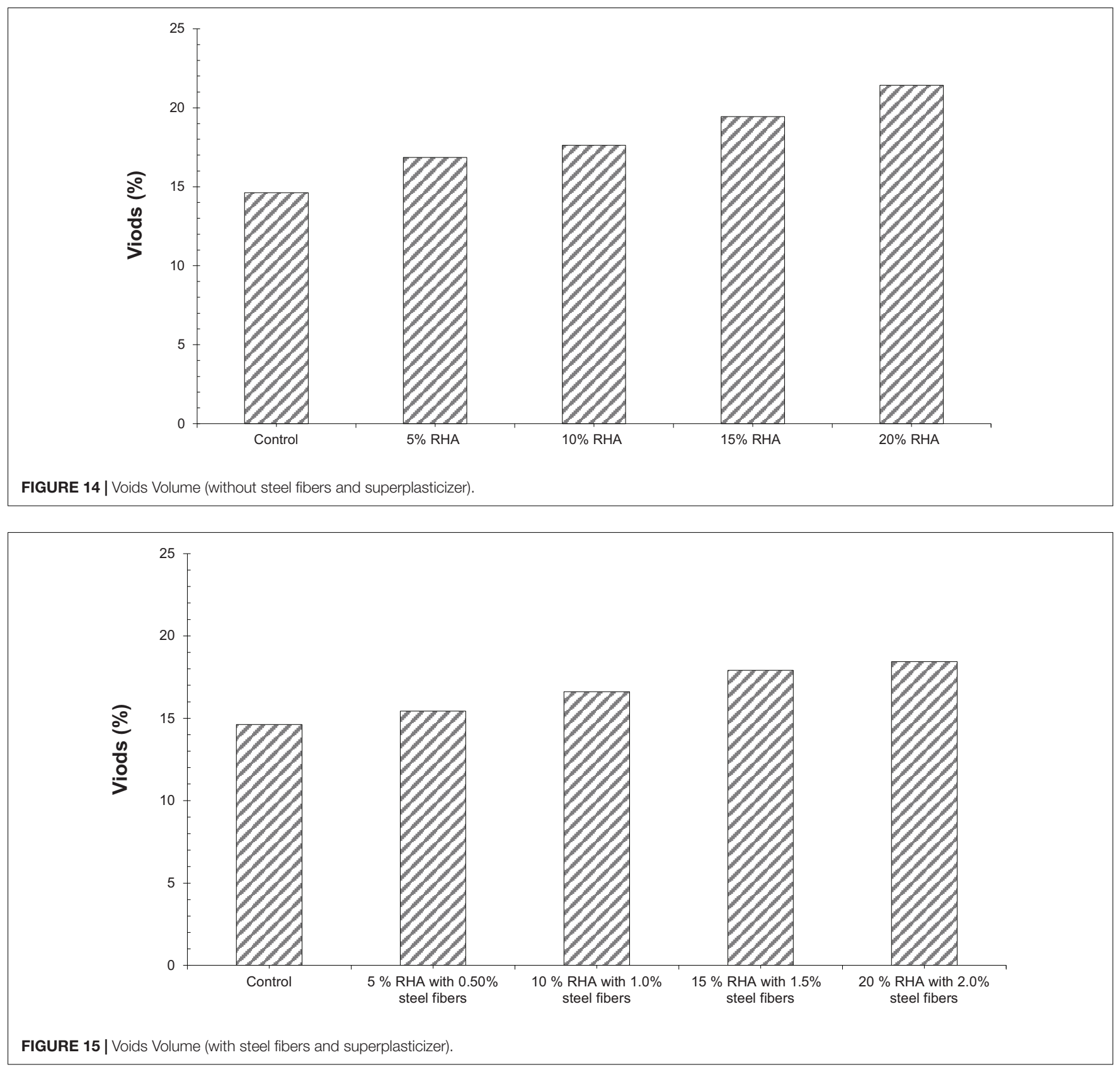
2,750 psi after 21 days curing, and 2,910 psi after 28 days of curing. RHA reduces the strength due to its porous nature which creates porous concrete and leads to less packing density, which in turn results in less strength. RHA reduces workability due to its fineness and porous nature which increases compaction, leading to pore voids in hardened concrete, resulting in less split tensile strength. Also, RHA absorbs more water which affects the hydration process due to lack of water (Nehdi et al., 2003), superplasticizer (MacInnis and Racic, 1986), and steel fiber (Vairagade and Kene, 2012; Ahmad et al., 2020a) increased strength. For 5\% cement substituted with Rice Husk Ash (RHA), and also incorporating steel fibers and superplasticizer in concrete, the decrease in strength was $4.6,3.3$, and $3.0 \%$ after 7,21 , and 28 days of curing, respectively, as in comparison to control sample (with superplasticizer and steel fibers).

For $10 \%$ substitution of cement with Rice Husk Ash including steel fibers and superplasticizer in concrete, strength was reduced $9.4,10.1$, and $10.5 \%$ after 7,21 , and 28 days of curing, respectively, as compared to control sample (with superplasticizer and steel fibers). For $15 \%$ cement substituted with Rice Husk Ash including steel fibers and superplasticizer in concrete, the decrease in strength was $15.2,17.0$, and $17.3 \%$ after 7,21 , and 28 days of curing, respectively, as compared to the control sample (with superplasticizer and steel fibers). When 20\% cement replaced with Rice Husk including steel fibers and superplasticizer in concrete, the decrease in strength was 22.4, 24.2, and $25.5 \%$ after 7,21 , and 28 days of curing, respectively, as compared to reference samples (with superplasticizer and steel fibers).

A relative analysis was carried out in which the 28-days curing age compressive strength of the control mix was considered the relating mix, and from this, different mixes with varying percentages of RHA and steel fiber (SF) were compared, as displayed in Figure 5. On day 7 of curing, compressive strength was about $21 \%$ less than that of the control (28 days) at $10 \%$ substitution with RHA and $1.0 \%$ SF. On day 21 of curing, compressive strength was about $13 \%$ less than that of the control (28 days) at $10 \%$ substitution with RHA and $1.0 \%$ SF. On 28 days of curing, compressive strength was about $4.0 \%$ less than that of the control (28 days) at $20 \%$ substitution with RHA and $1.0 \%$ SF.

It was observed from the test outcome that by adding superplasticizer and steel fibers the concrete compressive strength improved by a significant margin. For $10 \%$ cement replaced with Rice Husk Ash and also using steel fibers and superplasticizer, on average about $4.0 \%$ strength was reduced. Thus, up to $10 \%$ replacement of cement with Rice Husk Ash is allowed in concrete without a noticeable effect in compressive strength.

\section{Split Tensile Strength Test on Concrete Cylinders With Cement Substituted With Rice Husk Ash (With the Absence of Steel Fibers)}

Split tensile strength test is carried out as per ASTM C 496 (Designation, 1976). Results of the split tensile strength test on concrete cylinders with Rice Husk Ash substituted with cement (without steel fibers) are displayed in Figure 6. It is recognized that concrete strength increases with an increase in curing days. Split tensile strength values followed the same strength reduction pattern in concrete. It has been also reported that split tensile strength behaves in a similar pattern with the incorporation of RHA (Sakr, 2006). For normal concrete with 0\% RHA, concrete split tensile strength was 265 psi after 7 days of curing, 295 psi after 21 days of curing, and 335 psi after 28 days of curing. For $5 \%$ of cement replaced with RHA, the strength decrease was 4.4, 4.2 , and $3.8 \%$ after 7,21 , and 28 days of curing, respectively, as in comparison to control specimens. For $10 \%$ cement substituted with RHA, the strength decrease was 9.6, 11.9, and $13.0 \%$ after 7 , 21 , and 28 days of curing, respectively, as compared to reference samples. For $15 \%$ cement replaced with Rice Husk Ash, the decrease in strength was $16.1,17.2$, and $19.4 \%$ after 7,21 , and 28 days of curing, respectively, as compared to control samples. For $20 \%$ replacement of cement with Rice Husk Ash, the strength decrease was 25.2, 26.3, and 26.9\% after 7, 21, and 28 days of curing, respectively, as compared to control samples. From the results, it is noted that with the increase in dosage of RHA with cement replacement, the concrete split tensile strength was continuously reduced. On substitution of $10 \%$ cement with RHA on average a $12 \%$ decrease in compressive strength was seen. By further increasing the dose of RHA, concrete strength would be affected significantly. Thus, up to $10 \%$ substitution of RHA with cement is allowed in concrete without a notable effect in split tensile strength. RHA reduces split tensile strength due to its porous nature, which creates porous concrete, leading to less packing density and, in turn, less strength. It is worth mentioning here that RHA affects split tensile strength more than compressive strength; compressive strength reduced only $9.0 \%$ while split tensile strength reduced about $14 \%$ at $10 \%$ substitution of RHA. Steel fiber improves split strength but RHA reduces it, which results strength approximately equal to the control. Furthermore, both steel and RHA reduce workability which also results in lower strength. But overall, the results show that strength is comparable to control with the incorporation of RHA. Thus, it is a good choice to use RHA instead of cement.

A relative analysis was carried out in which the 28-day split tensile strength of the control mix was considered the reference mix, and from this, different mixes with varying percentages of were compared, as shown in Figure 7.

On 7 days of curing, split tensile strength was about $29 \%$ below that of the reference specimen (28 days) at $10 \%$ substitution with RHA. As compared to the control, 20\% substitution with RHA showed $41 \%$ less split tensile strength. On day 21 of curing, split tensile strength was about $32 \%$ below that of the reference specimen (28 days) at 10\% substitution with RHA. As compared to the control, $20 \%$ substitution with RHA showed $36 \%$ below split tensile strength at 21 days curing. On day 28 of curing, split tensile strength was about $14 \%$ below that of the reference specimen (28 days) at 10\% substitution with RHA.

\section{Split Tensile Strength Test on Concrete Cylinders With Cement Substituted With Rice Husk Ash (With Steel Fibers and Superplasticizer)}

Figure 8 illustrates various concrete split tensile strengths in which the cement is replaced with varying doses of RHA (with steel fibers and superplasticizer) with the 7,21, and 28 days of curing age. 
Normal concrete with $0 \%$ Rice Husk Ash demonstrated a concrete split tensile strength of 258 psi after 7 days of curing, 279 psi after 21 days of curing, and 294 psi after 28 days of curing. For 5\% cement substituted with RHA, the strength decrease was $3.5,3.8$, and $3.0 \%$ after 7,21 , and 28 days of curing, respectively, as in comparison to control specimens. For $10 \%$ cement substituted with RHA, the strength decrease was 7.2, 7.6 , and $6.8 \%$ after 7,21 , and 28 days of curing, respectively, as compared to reference samples. For $15 \%$ of cement replaced with Rice Husk Ash, the decrease in strength was 14.3, 14.9, and 15.3\% after 7, 21, and 28 days of curing, respectively, as in comparison to control specimens. For $20 \%$ substitution of cement with RHA, the strength reduction was $21.9,22.8$, and $23.3 \%$ after 7,21 , and 28 days of curing, respectively, as compared to control samples.

A relative analysis was carried out in which the 28-day split tensile strength of the control mix was considered the reference mix, and varying percentages of RHA and steel fiber (SF) are compared, as shown in Figure 9.

On day 7 of curing, split tensile strength was about 33\% below that of the reference mix (28 days) at $10 \%$ substitution with RHA and $10 \%$ of SF. On day 21 of curing, split tensile strength was about $19 \%$ below that of the reference mix (28 days) at $10 \%$ substitution with RHA and $2.0 \%$ SF. On 28 days of curing, split tensile strength was only $6.0 \%$ less than that of the control (28 days) at $10 \%$ substitution with RHA and $1.0 \%$ SF.

From the outcomes, it is perceived that by increasing the percentage of cement substitution with RHA, the concrete split tensile strength continuously decreased. On substitution of $10 \%$ RHA with cement, on average a $6.0 \%$ decrease in split tensile strength at 28 days was noted. By further increasing the percentage of RHA, concrete strength would be affected significantly. Thus, up to $10 \%$ substitution with cement RHA is allowed in concrete without a notable effect in split tensile strength.

\section{Durability Water Absorption}

Water absorption is an indirect measurement of concrete durability and is carried out as ASTM C 642-13 (C642-13 A, 2013). Most harmful chemicals are present in water. These chemicals react with concrete constituents, which changes the properties of concrete. Extra water present in the pores of concrete undergo a freeze and thaw effect because of changes in temperature, which results in cracks in the concrete (Kurda et al., 2019). The water absorption test was performed on those samples which were only cured in water for 28 days, the results of which are shown in Figure 10. General trends show that the water absorption increased as the percentages of RHA increased from 0 to $20 \%$. It has been also reported that water absorption increases with the addition of RHA (Kishore et al., 2011). According to test observation, maximum water absorption was $6.55 \%$ which increased to $8.39 \%$ when $20 \%$ Rice Husk Ash (RHA) was utilized in place of cement without adding steel fibers and superplasticizer.

The water absorption considerably decreased with the incorporation of steel fibers and superplasticizer, as shown in
Figure 11. The reduction in water absorption is because of the rise in workability superplasticizer (Alsadey, 2015) as well as the crack prevention of steel fibers resulting in fewer voids. It has been reported that $\mathrm{SF}$ reduces water absorption due to crack prevention (Ahmad et al., 2020b). An increase in water absorption signifies lower durability of concrete when adding higher percentages of RHA without the addition of steel fibers and superplasticizer.

\section{Density}

The density test of concrete is carried out as per ASTM C 64213 (C642-13 A, 2013). Figure 12 illustrates concrete density in detail, which is determined by using concrete cylindrical samples made with varying percentages of RHA, steel fibers, and superplasticizer.

Density decreases as the percentage of RHA increases, with a maximum density of $0 \%$ substitution of RHA while minimum density was obtained at $20 \%$ substitution of RHA. This is due to the physical nature of RHA, which is porous in nature, as well as the larger surface area (Bui et al., 2005) which results in decreased workability resulting in porous concrete, which ultimately decreases density.

Steel fibers and superplasticizer are added to offset this negative effect of (decreasing density) RHA, as shown in Figure 13. Superplasticizer enhances the workability of concrete (Alsadey, 2015) by creating an opposite charge on the particles which repel each other and, as a result, create more dense concrete. Also, steel fibers prevent the creation of cracks (Chang and Chai, 1995), resulting in a reduction in void content which leads to enhanced density of concrete. So, the addition of SFs would lead to increased tensile properties of concrete, and as a result, it would restrict the formation and development of initial cracks (Huang and Xie, 2011).

Overall, the diminishing value of density indicates that an increase in void content in concrete causes less durable and lower strength as compared to normal concrete. But by replacing cement with RHA and adding steel fibers enhances the strength value of concrete, which is both economical and environmentally friendly.

\section{Volume of Voids}

The results of the volume of voids are evaluated using concrete cylinders as per ASTM C 642-13 (C642-13 A, 2013) with different percentages of RHA and the result was then compared to control samples as shown in Figure 14. Voids in concrete indirect measurements of the durability of concrete (Ahmad et al., 2020a). The value of voids' volume in the normal concrete mix was $14.62 \%$, which then increased to $21.42 \%$ with the replacement of cement with $20 \%$ RHA with no steel fibers. Furthermore, the addition of steel and superplasticizer showed some improvement with the reduction of voids in concrete as shown in Figure 15.

The volume of voids increased from 14.62 to $18.45 \%$. This is due to fact that steel fibers act as crack arresters and prevent the propagation of a crack in hardening concrete (Ahmad et al., 2020b). It has also been reported that, with the addition of superplasticizer, the workability of concrete improved, results in decreased voids in concrete (Borsoi et al., 2000; 
Ahmad et al., 2020b). Increasing voids' volume depicts lower bonding in concrete and can raise the ultrasonic pulse velocity of concrete (Ahmad et al., 2020b).

\section{CONCLUSION}

The current research was intended to analyze the impact of the utilization of changing doses of RHA as a fractional substitution of cement in concrete blends. For this, 0, 5, 10, 15, and 20\% RHA was presented in cement blends. Properties of the concrete mix, like its compressive and split tensile strength, density, water absorption, and the volume of voids, were evaluated at 7,21, and 28 days. The aftereffects of these experiential examinations have been dissected and the significant findings of this investigation are introduced as follows.

- The compressive strength of concrete decreased considerably with an increasing percentage of RHA. Therefore, adding steel fibers and superplasticizer was important because steel fibers provide ductility to concrete and, while RHA and steel fibers diminish concrete workability, superplasticizer helps concrete to be flowable and easy to work with.

- Concrete tensile strength is around $10-15 \%$ of its compressive strength. Adding steel fibers with

\section{REFERENCES}

Ahmad, J., Al-Dala'ien, R. N. S., Manan, A., and Zaid, O. (2020a). Evaluating the effects of flexure cracking behaviour of beam reinforced with steel fibres from environment affect. J. Green Eng. 10, 4998-5016.

Ahmad, J., Manan, A., Ali, A., Waleed Khan, M., Asim, M., and Zaid, O. (2020b). A study on mechanical and durability aspects of concrete modified with steel fibers (SFs). Civil Eng. Arch. 8, 814-823. doi: 10.13189/cea.2020.0 80508

Ahmad, J., Tufail, R. F., Aslam, F., Mosavi, A., Alyousef, R., Faisal Javed, M., et al. (2021). A step towards sustainable self-compacting concrete by using partial substitution of wheat straw ash and bentonite clay instead of cement. Sustainability 13:824. doi: 10.3390/su13020824

Alsadey, S. (2015). Effect of superplasticizer on fresh and hardened properties of concrete. J. Agric. Sci. Eng. 1, 70-74.

ASTM C 33/C33M (2008). Stand Specif Concr Aggregates. West Conshohocken: ASTM, 498-505.

Borsoi, A., Collepardi, S., Coppola, L., Troli, R., and Collepardi, M. (2000). Effect of superplasticizer type on performance of high-volume fly ash concrete. ACI Spec. Publ. 195, 17-28.

Bui, D. D., Hu, J., and Stroeven, P. (2005). Particle size effect on the strength of rice husk ash blended gap-graded Portland cement concrete. Cem. Concr. Compos. 27, 357-366. doi: 10.1016/j.cemconcomp.2004.05.002

C39/C39M A (2003). Standard Test Method for Compressive Strength of Cylindrical Concrete Specimens. Annu B ASTM Stand. West Conshohocken: ASTM.

C642-13 A (2013). Standard Test Method for Density, Absorption, and Voids in Hardened Concrete. West Conshohocken, PA: ASTM Int.

Cement AP ASTM C150 of the following type: 1 . Concr which will be contact with Sew Type II, Moderate Sulfate Resist 2. Available at: https://www.cement.org/ cement-concrete/concrete-materials/cement-types

Chang, D.-I., and Chai, W.-K. (1995). Flexural fracture and fatigue behavior of steel-fiber-reinforced concrete structures. Nucl. Eng. Des. 156, 201-207. doi: 10.1016/0029-5493(94)00946-v

Designation, A. (1976). C496-71. Stand Method Test Split Tensile Strength Cylind Concr Specimens. West Conshohocken: ASTM. superplasticizer in concrete, in which cement is replaced with RHA in different percentages, improved concrete tensile strength remarkably as compared to concrete compressive strength.

- An increase in volume voids and water absorption and decrease in concrete density was detected when RHA was added up to $20 \%$.

- $10 \%$ replacement of cement with RHA was considered good, as it did not affect concrete that much, and the introduction of steel fibers and admixtures like superplasticizer can make concrete a more economically viable option for the construction industry.

\section{DATA AVAILABILITY STATEMENT}

The original contributions presented in the study are included in the article/supplementary material, further inquiries can be directed to the corresponding author/s.

\section{AUTHOR CONTRIBUTIONS}

OZ has written the main text, JA revised the paper, MSS secured the funding and helped in methodology. FA has helped in data collection.

ENTS (2009). 934-2 “Admixtures For Concrete, Mortar and Grout-Part 2: Concrete Admixtures; Definitions, Requirements, Conformity, Marking and Labelling”. London: BSI.

Ferraro, R. M., Nanni, A., Vempati, R. K., and Matta, F. (2010). Carbon neutral offwhite rice husk ash as a partial white cement replacement. J. Mater. Civ. Eng. 22, 1078-1083. doi: 10.1061/(asce)mt.1943-5533.0000112

Giaccio, G., de Sensale, G. R., and Zerbino, R. (2007). Failure mechanism of normal and high-strength concrete with rice-husk ash. Cem. Concr. Compos. 29, 566-574.

High-Range W-RA, Admixture R ASTM C 494/C 494M. Type F. Available at: https: //www.astm.orgDATABASE.CART/HISTORICAL/C494C494M-08A.htm

Huang, G., and Xie, X. (2011). Experimental study on the effect of nano-SiO 2 to durability in hydraulic concrete. Yellow River 33, 138-140.

James, J., and Rao, M. S. (1986). Reactivity of rice husk ash. Cem. Concr. Res. 16, 296-302. doi: 10.1016/0008-8846(86)90104-3

Jaturapitakkul, C., and Roongreung, B. (2003). Cementing material from calcium carbide residue-rice husk ash. J. Mater. Civ. Eng. 15, 470-475. doi: 10.1061/ (asce)0899-1561(2003)15:5(470)

Kishore, R., Bhikshma, V., and Prakash, P. J. (2011). Study on strength characteristics of high strength rice husk ash concrete. Proc. Eng. 14, 2666-2672. doi: 10.1016/j.proeng.2011.07.335

Kurda, R., de Brito, J., and Silvestre, J. D. (2019). Water absorption and electrical resistivity of concrete with recycled concrete aggregates and fly ash. Cem. Concr. Compos. 95, 169-182. doi: 10.1016/j.cemconcomp.2018.10.004

MacInnis, C., and Racic, D. (1986). The effect of superplasticizers on the entrained air-void system in concrete. Cem. Concr. Res. 16, 345-352. doi: 10.1016/00088846(86)90110-9

Materials ASFTA (2012). ASTM C39/C39M-12 Standard Test Method for Compressive Strength of Cylindrical Concrete Specimens. West Conshohocken: ASTM.

Mehta, P. K. (1992). Rice Hush Ash-A unique supplementary cementing material. Adv. Concr. Technol. 154, 531-542.

Nehdi, M., Duquette, J., and El Damatty, A. (2003). Performance of rice husk ash produced using a new technology as a mineral admixture in concrete. Cem. Concr. Res. 33, 1203-1210. doi: 10.1016/s0008-8846(03)00038-3 
Nuruddin, F., Demie, S., Memon, F. A., and Shafiq, N. (2011). Effect of superplasticizer and $\mathrm{NaOH}$ molarity on workability, compressive strength and microstructure properties of self-compacting geopolymer concrete. World Acad. Sci. Eng. Technol. 75, 187-194.

O'Connell, M. T., Shepherd, T. D., O'Connell, A. M. U., and Myers, R. A. (2007). Long-term declines in two apex predators, bull sharks (Carcharhinus leucas) and alligator gar (Atractosteus spatula), in lake pontchartrain, an oligohaline estuary in southeastern Louisiana. Estua. Coasts 30, 567-574. doi: 10.1007/ bf02841954

Qing-ge, F., Qing-yu, L., Qi-jun, Y., San-ying, Z., Lu-feng, Y., and Sugita, S. (2004). Concrete with highly active rice husk ash. J. Wuhan Univ. Technol. Sci. Ed. 19, 74-77.

Sakr, K. (2006). Effects of silica fume and rice husk ash on the properties of heavy weight concrete. J. Mater. Civ. Eng. 18, 367-376. doi: 10.1061/(asce)08991561(2006)18:3(367)

Tangchirapat, W., Jaturapitakkul, C., and Kiattikomol, K. (2009). Compressive strength and expansion of blended cement mortar containing palm oil fuel ash. J. Mater. Civ. Eng. 21, 426-431. doi: 10.1061/(asce)0899-1561(2009)21:8(426)

Tay, J.-H. (1990). Ash from oil-palm waste as a concrete material. J. Mater. Civ. Eng. 2, 94-105. doi: 10.1061/(asce)0899-1561 (1990)2:2(94)

Toutanji, H. A. (1999). Properties of polypropylene fiber reinforced silica fume expansive-cement concrete. Constr. Build Mater. 13, 171-177. doi: 10.1016/ s0950-0618(99)00027-6

Udoeyo, F. F., and Dashibil, P. U. (2002). Sawdust ash as concrete material. J. Mater. Civ. Eng. 14, 173-176. doi: 10.1061/(asce)0899-1561(2002)14:2(173)
Uduweriya, R., Subash, C., Sulfy, M. M. A., and De Silva, S. (2010). "Investigation of compressive strength of concrete containing rice-husk-ash," in Proceedings of the International Conference on Sustainable Built Environment (ICSBE-2010), Kandy.

Vairagade, V. S., and Kene, K. S. (2012). Introduction to steel fiber reinforced concrete on engineering performance of concrete. Int. J. Sci. Technol. Res. 1:141.

Vijai, K., Kumutha, R., and Vishnuram, B. G. (2012). Effect of inclusion of steel fibres on the properties of geopolymer concrete composites. Asian J. Civil Eng. 13, 377-385.

Xu, W., Lo, T. Y., and Memon, S. A. (2012). Microstructure and reactivity of rich husk ash. Constr. Build Mater. 29, 541-547. doi: 10.1016/j.conbuildmat.2011. 11.005

Zain, M. F. M., Islam, M. N., Mahmud, F., and Jamil, M. (2011). Production of rice husk ash for use in concrete as a supplementary cementitious material. Constr. Build Mater. 25, 798-805. doi: 10.1016/j.conbuildmat.2010.07.003

Conflict of Interest: The authors declare that the research was conducted in the absence of any commercial or financial relationships that could be construed as a potential conflict of interest.

Copyright (c) 2021 Zaid, Ahmad, Siddique and Aslam. This is an open-access article distributed under the terms of the Creative Commons Attribution License (CC BY). The use, distribution or reproduction in other forums is permitted, provided the original author(s) and the copyright owner(s) are credited and that the original publication in this journal is cited, in accordance with accepted academic practice. No use, distribution or reproduction is permitted which does not comply with these terms. 